\title{
ポリビニルアルコール水溶液ゲルの粘着性と粘弾性
}

\author{
漆崎文男, ${ }^{*, a}$ 山口 洋, ${ }^{a}$ 水町 浩 $^{b}$ \\ 大正製薬株式会社総合研究所第 2 製剂研究室 ${ }^{a}$ \\ 東京大学農学部林産学科高分子材料化学教室 ${ }^{b}$
}

\section{Pressure Sensitive Adhesion and Viscoelasticity of Polyvinyl Alcohol Aqueous Gel}

\author{
Fumio UrUshizaki, ${ }^{*, a}$ Hiroshi Yamaguchi, ${ }^{a}$ \\ and HIROSHI MIZUMACHI ${ }^{b}$ \\ Department of Second Pharmaceuticals, Research Center, Taisho Pharmaceutical \\ Co. Ltd., 'Y Yoshino-cho, 1-403, Ohmiya-shi, Saitama, 330, Japan and \\ Laboratory of Chemistry of Polymeric Materials, Department of \\ Forest Products, Faculty of Agriculture, The University of \\ Tokyo, ${ }^{b}$ Yayoi 1-1-1, Bunkyo-ku, Tokyo, 113, Japan
}

(Received December 16, 1985)

Polyvinyl alcohol (PVA) aqueous solutions with high water content were repeatedly frozen and defrosted to obtain PVA hydrogels with high elasticity.

Tack and viscoelasticities such as storage modulus and loss tangent of the PVA hydrogels were determined as a function of molecular weight, saponification value of PVA, number of cycles of freezing-defrosting procedure or temperature of defrosting, in order to obtain an information on utilities of the materials as prepared poultices and transdermal therapeutic system.

Correlation matrix method of multiregression analysis was applied to our data on tack and viscoelasticities of gels, and it was found that there was a significant correlation between tack and storage modulus as well as loss tangent of the materials.

Tack, which is one of the most essential properties of pressure sensitive adhesives as prepared poultices and drug delivery system, can easily be predicted, if we measure viscoelasticities of the materials.

Keywords_- polyvinyl alcohol; hydrogel; tack; vicoelasticity; modulus; poultice; transdermal therapeutic system; pressure sensitive adhesive

凍結解凍を繰り返して作成したポリビニルアルコール水溶液ゲル (PVA 水溶液ゲル) は高含水で高弾性を示 し, 機械的な強度も高い事が渡瀬 ${ }^{1)}$ より報告されている.

一方, 水溶性高分子の含水ゲルは皮膚の角質が水和により薬剤の吸収が改善されることから成形湿布剂をはじ め経皮吸収型貼付剤の基剤として応用されている．ポリアクリル酸ナトリウム，ゼラチン，寒天などの水溶液ゲ ルは機械的な強度が乏しく，したがってこれらの欠点を補ならため，ホルムアルデヒド，グルタールアルデヒド， ヘキサメチレンジアミン，二価金属塩などを添加して架橋するか，あるいはガンマー線を照射し2）架橋して機械 的な強度を改善している。しかし, 添加物による架橋, あるいは放射線による架橋は生体への影響が考兄られる ばかりでなく，配合薬剤への影響が考えられる。

PVA 水溶液ゲルは架橋剂などの添加物の配合あるいは放射線の照射などによらず，単に凍結解凍の物理的な 方法により高含水で高弾性が得られることから, 成形湿布剤などの経皮吸収型貼付製剤の基剤への利用のためゲ ルの粘着性及び粘弾性を測定し, さらに相関性を求めた. すなわち PVA 水溶液ゲルは, その粘着性がポリビニ ルアルュール (PVA) のケン化度, 分子鎖長, 凍結温度, 凍結時間, 解凍温度, 解凍時間, 凍結解凍操作の反復数 などにより影響を受けることから，粘弾性体として静的弾性，動的粘弾性を測定し，粘着性と粘弾性を相関マト リックス法3)により比較検討して関連性を求めた. 
その結果 PVA 水溶液ゲルの粘着性は静的弾性, 貯蔵弾性率, 損失正接 (損失 $\tan \delta$ ) に高い相関性があり, 損 失弾性率とは相関性が無いことが分かった。

\section{実験 の 部}

1. 試料 PVA はクラレポバール (電気化学工業株式会社) 及びゴーセノール (日本合成化学工業株式会社) のコマーシャル・グレードを用い, それぞれのけん化度, 粘度, ゲル形成性を Table I に示す.

PVA 水溶液ゲルの作成は粘着性測定及び静的弾性パラメーター用と動的粘弾性測定用の 2 種類を作製した. 作製は以下の手順で行った. PVA 水溶液を沸騰水浴上で加熱し，かきまぜて均一に溶解する. 静置して PVA 水 溶液中の気泡を取り除き, 室温まで放冷し，あらかじめ両面粘着テープで紙を貼り合わせたガラス板 $(3.0 \times 19.0$ $\left.\mathrm{cm}^{2}\right)$ 上に均等にひろげる.PVA 水溶液ゲルの厚さは枠の高さにより調節する.ささらにポリェステル製の剥離フ ィルムで被い, 種々の条件により凍結解凍を行う.

動的粘弾性測定用は室温まで放冷後, 内径 $2 \mathrm{~cm}$, 長さ $3 \mathrm{~cm}$ の円筒中に注入し, 同筒の両端は水分の蒸発を防 止するためサランフィルムを用いてシールし, 種々の条件により凍結解凍を行った.

凍結は $-5 \pm 1^{\circ} \mathrm{C}$ の冷凍庫に保存した. 解凍は $5,25,40^{\circ} \mathrm{C}$ の各温度で行った. 凍結解凍の反復は 4 回まで行 った.

この凍結解凍中の重量変化, 体積変化及び離水はほとんど見られなかった.

2. 測定及び測定装置 2.1 ローリングシリンダー法タック測定一ータック (初期粘着) の測定は Fig. 1 に

TABLE I. Polyvinyl Alcohol (PVA) for Determination of Rolling

Friction and Viscoelasticity

\begin{tabular}{|c|c|c|c|c|}
\hline $\begin{array}{c}\text { Test } \\
\text { sample }\end{array}$ & $\begin{array}{l}\text { Saponification } \\
\text { value }(\mathrm{mol} \%)\end{array}$ & $\begin{array}{l}\text { Viscosity } \\
\text { (cP) }\end{array}$ & Gelation $^{b)}$ & Makers name \\
\hline K-17E & $97.8-98.5$ & $28-32$ & 0 & $\begin{array}{l}\text { Denka } \\
\text { Poval }\end{array}$ \\
\hline$K-20$ & $97.5-98.5$ & $38-45$ & $\bigcirc$ & $\begin{array}{l}\text { Denka } \\
\text { Poval }\end{array}$ \\
\hline $\mathrm{K}-24 \mathrm{E}$ & $97.8-98.5$ & $57-67$ & $\bigcirc$ & $\begin{array}{l}\text { Denka } \\
\text { Poval }\end{array}$ \\
\hline NH-20 & $98.5-99.4$ & $35-43$ & 0 & $\begin{array}{l}\text { Nihon Gohsey } \\
\text { Gohosenol }\end{array}$ \\
\hline AH-17 & $97.0-98.5$ & $25-30$ & 0 & $\begin{array}{l}\text { Nihon Gohsey } \\
\text { Gohosenol }\end{array}$ \\
\hline AH-22 & $97.5-98.5$ & $50-66$ & 0 & $\begin{array}{l}\text { Nihon Gohsey } \\
\text { Gohosenol }\end{array}$ \\
\hline AH-26 & $97.0-98.8$ & $58-66$ & $\times$ & $\begin{array}{l}\text { Nihon Gohsey } \\
\text { Gohosenol }\end{array}$ \\
\hline $\mathrm{CH}-23$ & $86.5-89.0$ & $48-56$ & $\times$ & $\begin{array}{l}\text { Nihon Gohsey } \\
\text { Gohosenol }\end{array}$ \\
\hline
\end{tabular}

a) Viscosity of $4 \%$ aqueous solution.

b) Gelation of $15 \%$ aqueous solution on freezing at $-5^{\circ} \mathrm{C}$ in $20 \mathrm{~h}$ and defrosting at room temperature in $4^{\circ} \mathrm{C}$.

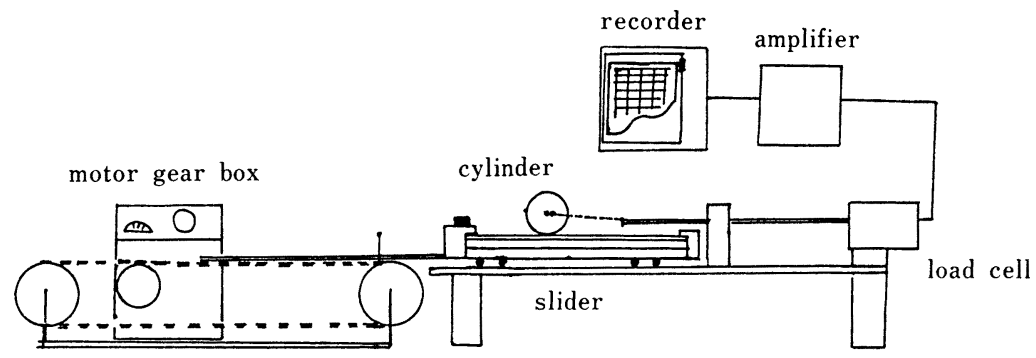

Fig. 1. Apparatus for Determining Rolling Cylinder Tack 
示すように白作のローリングシリンダー法により行 った．本法は任意の初速度で，後は自ら転がるにま かせるという JIS 法, ${ }^{4)}$ 医薬品製造指針の特殊製剂 試験の粘着試験法 ${ }^{5)}$ と異なり, シリンダーの回転速 度は任意の一定速度で牽引することができる.

これらの方法の理論的解析については水町 ${ }^{6)}$ の報 告を参照されたい.

Fig. 2 に予備的に測定したシリンダー径及びシリ ソダー重量と同一 PVA 水溶液ゲルの粘着性の関係 を示したが, 本研究では直径 $2 \mathrm{~cm}$ のンリンダーを 用い, 率引速度 $118.3 \mathrm{~cm} / \mathrm{min}$ から $1583.1 \mathrm{~cm} / \mathrm{min}$

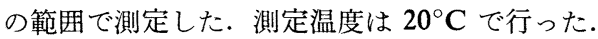

2.2 静的弾性パラメーター測定一一静的弾性パ ラメーターの測定は不動工業製レオメーターNRM2010J-2W-L に理化学工業株式会社製多ペンレコー ダーR-32-XD を接続して用いた。測定にはタック を測定した PVA 水溶液ゲルを用いた。

測定に用いた PVA 水溶液ゲルは幅 $3.0 \mathrm{~cm}$, プ

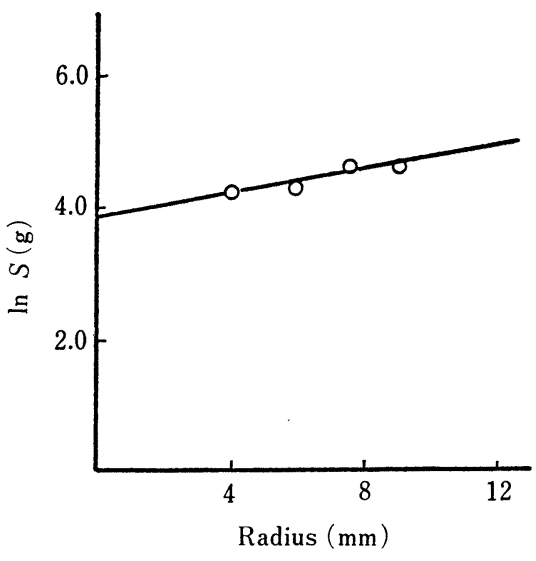

Fig. 2. Dependence of Rolling Cylinder Tack on Radius and Weight of a Cylinder

Radius (mm); $4 \quad 6 \quad 7.5 \quad 10$ Weight (g); $12.7 \quad 21.6 \quad 33.0 \quad 56.4$

ランジャー間の長さを $10 \mathrm{~cm}$ とした. 引張り速度 $6 \mathrm{~cm} / \mathrm{min}$ で伸びと応力の関係をもとめ, 伸び開始直後の接線

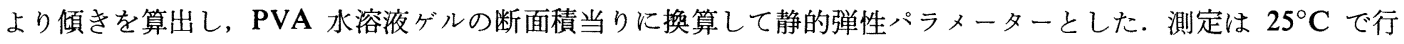
つた.

2.3 動的粘弾性測定一一動的粘弾性率 (貯蔵弾性率, 損失弾性率, 損失正接 (損失 $\tan \delta$ )) の測定は東洋精機製 作所株式会社製レオログラフーゲルを用いて測定した. 測定には PVA 水溶液ゲルの直径 $20 \mathrm{~mm}$, 長さ $30 \mathrm{~mm}$ の 円柱状のものを用いた. 測定の変位 $\pm 100 \mu \mathrm{m}$, 加振周波数 $2 \mathrm{~Hz}$ で測定した.

\section{実験 結果及び考察}

\section{PVA 水溶液ゲルの粘着性}

（1）PVA 分子鎖長とタックの関係凍結解凍により高含水で高弾性の含水ゲルを形成するのは完全ケン 化した PVA のみに生ずることが渡瀬ら"゙レより報告されている. しかし PVA が完全ケン化体であっても分子 鎖長により, その粘弾性が異なり, さらにはタックが異なってくると考えられる. 水溶性高分子の場合, 通常分 子量は分布を持つことから Table I に示すごとく，一定濃度における粘度で表示している. Fig. 3 に同一ケン化

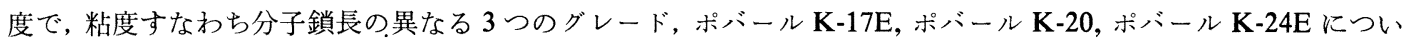
て牽引速度 (ローリングシリンダーの回転数で表示する. 率引速度 $v(\mathrm{~cm} / \mathrm{min})$ とローリングシリンダーの回転数 $\mathrm{rpm}$ は $V=8 / 7.1(\mathrm{rpm}+5)$ の関係がある) とタックの関係を示した結果である.

これら結果は牽引速度に対してタックが増大する傾向を示しており, 水町 ${ }^{8)}$ が報告した, 粘着剂の転がり摩擦 係数, すなわちタックと牽引の関係における, 粘着剤が軟かい粘弾性体の右上りの測定領域にあることが分かる. ポバール K-17E と K-20 は同様のタック特性を示すが, 分子量の大きな K-24E は粘着力が低下している.

（2） PVA 湿度とタックの関係ポバール K-20 を用いて, 濃度 $10-25 \% \mathrm{w} / \mathrm{v}$ の間で PVA 濃度と PVA 水溶液ゲルの粘着性の関係を示したのが Fig. 4 である.

タックに対する PVA の濃度の影響には明確な傾向は見られない. 10\% w/v の PVA 水溶液ゲルにおいては, 他の濃度のものと異なり, 測定中にゲルが破壊し, 測定用のシリンダーへ転着する, いわゆる凝集破壊が起こっ た.

（3）凍結解凍の反復回数とタックの関係＼cjkstart凍結解凍の反復回数のタックへの影響については, 凍結は $-5^{\circ} \mathrm{C}, 20$ 時間, 解凍は $25^{\circ} \mathrm{C}, 4$ 時間の条件で反復した. 反復回数とタックの関係を Fig. 5 に示す.

1 回の凍結解凍では高粘着性の含水ゲルが得られるが， 2 回以降は急激に粘着性が低下し，低下の傾向も凍結 解凍の回数の増加に従って増加する傾向を示す. 凍結解凍の反復回数を増すと, 同時に PVA 水溶液ゲルの硬化 も観察され，タックの低下はPVA 水溶液ゲルの硬化が 1 つの原因であると推察される. 


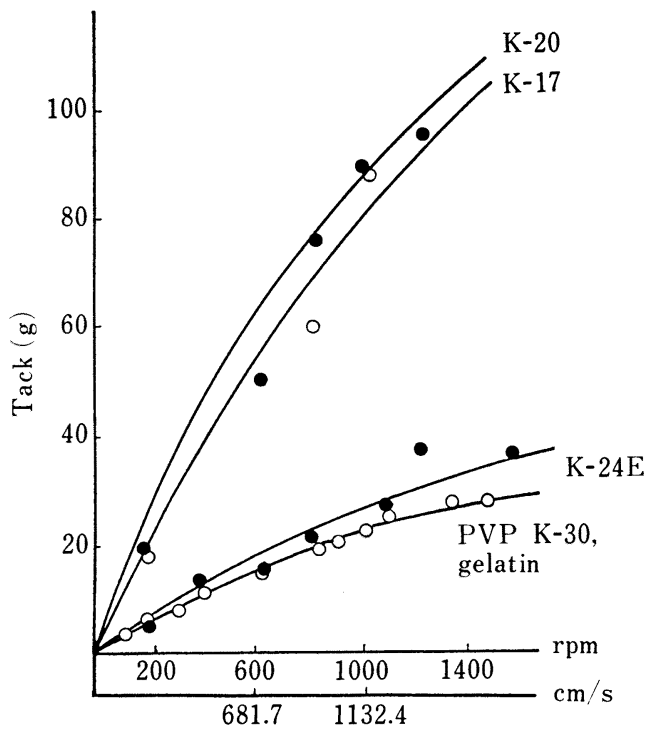

Fig. 3. Plot of Rolling Cylinder Tack as a Function of Velocity for PVA Hydrogels with Different Molecular Weights

Sample: $15 \%$ aqueous solution of PVA; freezing: $-5^{\circ} \mathrm{C}, 20 \mathrm{~h}$; defrosting: $25^{\circ} \mathrm{C}, 4 \mathrm{~h}$. Temperature: $20^{\circ} \mathrm{C}$, Radius of a cylinder: $1 \mathrm{~cm}$.

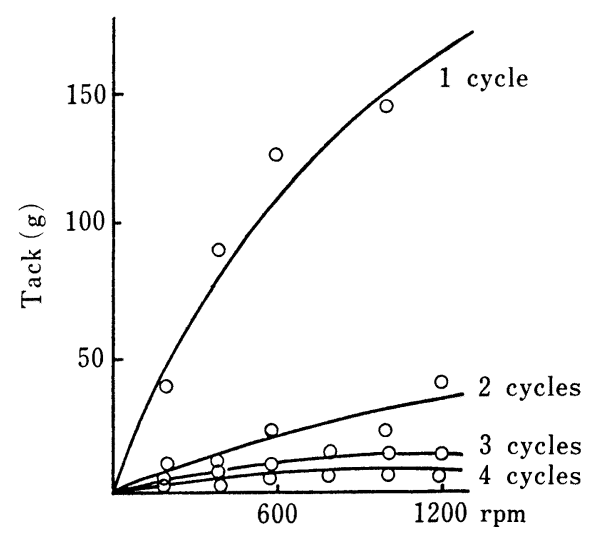

Fig. 5. Plot of Rolling Cylinder Tack as a Function of Velocity for PVA Hydrogels Prepared with Different Number of Freezing-Defrosting Cycles

Sample: $15 \%$ aqueous solution of Poval K-20; freezing: $-5^{\circ} \mathrm{C}, 20 \mathrm{~h}$; defrosting: $25^{\circ} \mathrm{C}, 4 \mathrm{~h}$. Temperature: $20^{\circ} \mathrm{C}$. Radius of a cylinder: $1 \mathrm{~cm}$.

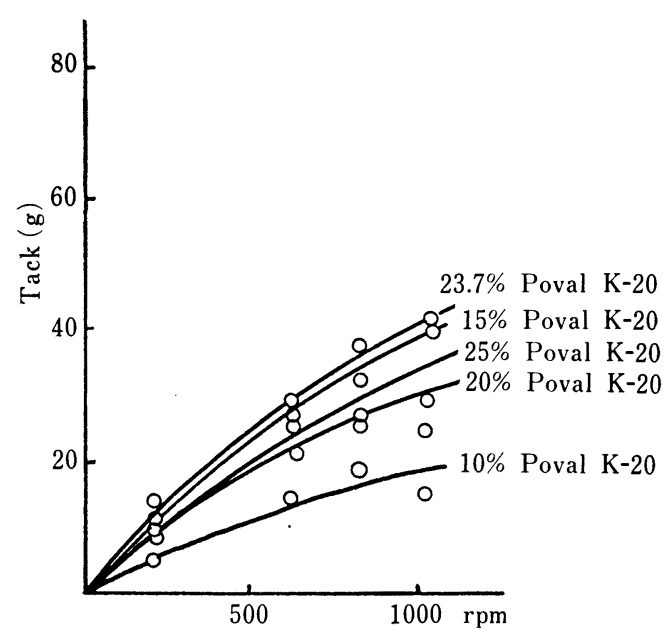

Fig. 4. Plot of Rolling Cylinder Tack as a Function of Velocity for PVA Hydrogels with Different Concentrations

Sample: Poval K-20; freezing: $-5^{\circ} \mathrm{C}, 20 \mathrm{~h}$; deforsting: $5^{\circ} \mathrm{C}, 4 \mathrm{~h}$. Temperature: $20^{\circ} \mathrm{C}$. Radius of a cylinder: $1 \mathrm{~cm}$.

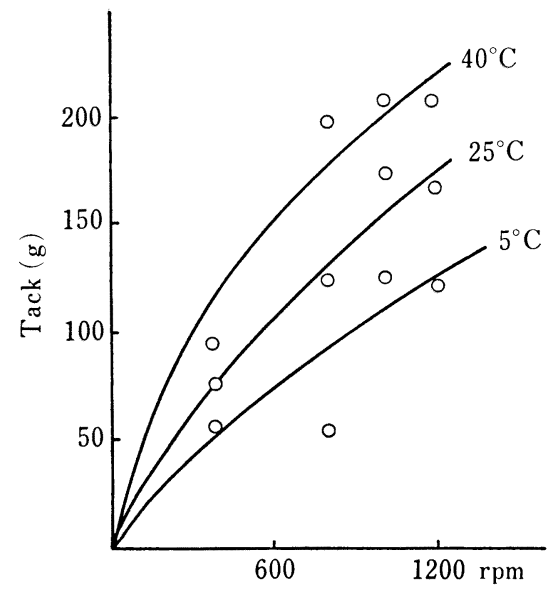

Fig. 6. Plot of Rolling Cylinder Tack as a Function of Velocity for PVA Hydrogels Prepared with Different Defrosting Temperatures

Sample: $15 \%$ aqueous solution of Poval K-20; freezing: $-5^{\circ} \mathrm{C}, 20 \mathrm{~h}$. Temperature: $20^{\circ} \mathrm{C}$. Radius of a cylinder: $1 \mathrm{~cm}$.

（4）タックに対する解凍温度の影響ＰVA 水溶液ゲルの粘弾性は凍結温度 ${ }^{1)}$ や凍結時間》)に影響を受け ることが知られているが, 解凍温度すなわち解凍時間によっても粘弾性すなわちタックが変化する事が予測され る. PVA の $15 \% \mathrm{w} / \mathrm{v}$ 水溶液ゲルを $-5^{\circ} \mathrm{C}, 20$ 時間の凍結により作成し, $5,25^{\circ} \mathrm{C}$ 及び $40^{\circ} \mathrm{C}$ に放置して解凍し た時のタックの変化を Fig. 6 に示した.

解凍温度が高い方がタックは高い傾向を示す. PVA 水溶液ゲルは約 $45^{\circ} \mathrm{C}$ から非可逆的なゾル化を起こすが, 
ゾル化を起こす温度までは粘弾性的な变化は無い。したがって，ある物性を持つ粘弾性体が各温度で各解凍温度 で可逆的なタックを示すのでは無く, 解凍温度により, それぞれの物性を示す.すなわち $5^{\circ} \mathrm{C} て ゙$ 解凍した PVA 水溶液ゲルの $25^{\circ} \mathrm{C}$ におけるタックは $25^{\circ} \mathrm{C}$ で解凍したものと同一では無い.

（5）タックに対する PVA 水溶液ゲルの厚さの影響タックに対する PVA 水溶液ゲルの厚さの影響を Fig. 7 に示す.

ゲルの厚さが増加するに従いタックは低下する傾向を示す．これは厚さにより解凍時間に若干の遅れを生じた 結果が 1 つの原因と考えられるが，シリンダーの回転で，一定の変位においてシリンダー表面と PVA 水溶液ゲ ルが表面破壊を起こすと仮定するならば，単位変位あたりの応力は PVA 水溶液ゲルの厚さが厚い方が小さい. したがってゲル厚が增加するに従ってタックは低下すると考えられる. 詳細な考察については水町ら ${ }^{8)}$ の報告を 参照されたい。

（6）静的弾性パラメーターの測定 静的弾性パラメーターの測定はタックを測定したサンプルの PVA 水 溶液ゲル部分をはがし取り，転着した紙を取り除き測定に用いた。結果を Fig. 8 に示す.

ポバール K-17E, ポバール K-20, ポバール K-24E の応力ー伸び曲線より, 同一ゲル化条件では分子量の増大に 従って硬い傾向があることが分かる. また凍結解凍の回数を増すことによっても硬化する傾向がある.

ゲルは約 3 倍程度伸すことが可能であるが, 変形が進行するに従い, 一定応力に対する変位が増大する, いわ ゆる粘弾性的な性質を示し，フックの弾性よりはずれてくる．したがって引張り開始直後の变位一応力曲線の接 線の傾きより，単位断面積当りに換算した結果を静的弾性パラィーターとした.

（7）動的粘弾性の測定とタック及び静的弾性パラメーターの関係タック及び静的弾性パラメーターを測 定した PVA 水溶液ゲルに対応した, 形状は異なるが同一条件で作成したゲルの動的粘弾性, すなわち貯蔵弾性 率, 損失弾性率, 損失正接 (損失 $\tan \delta$ ) を測定し, 製造条件, PVA の種類, タック及び静的弾性パラメーターと 対応させた結果を Table II に示した.

タックは重回帰分析3)による相関性を評価するため対数值で示した.

PVA の種類及び製造方法により貯蔵弾性率及び損失 $\tan \delta$ には变化が認められるが, 損失弾性率は変化が無

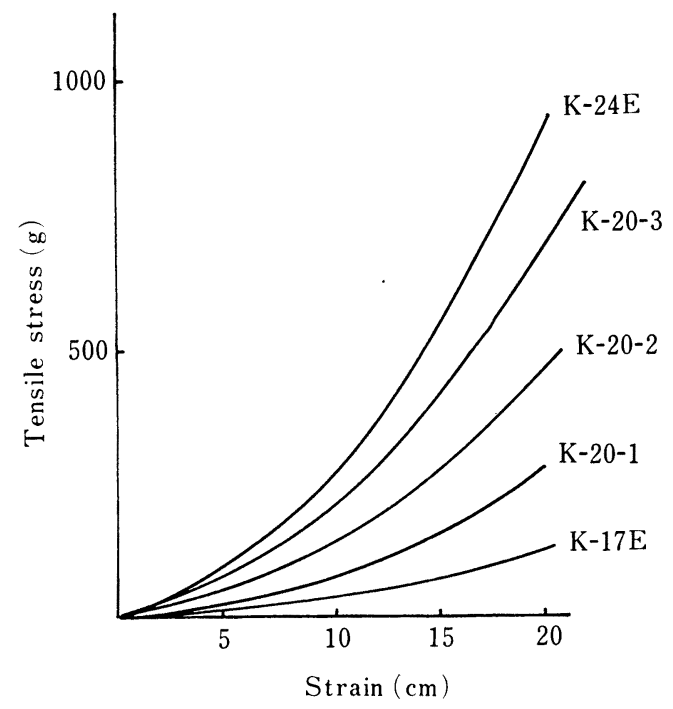

Fig. 8. Stress-Strain Curves of PVA Hydrogels at $24.5^{\circ} \mathrm{C}$

Samples: Poval K-20-1,a) Poval K-20-2,a) Poval K20-3, a) Poval K-24E, Poval K-17E; freezing: $-5^{\circ} \mathrm{C}$, $20 \mathrm{~h}$; defrosting: $20^{\circ} \mathrm{C}, 4 \mathrm{~h}$.

Apparatus: Rheometer (Fudou Kogyo). Speed: $6 \mathrm{~cm} / \mathrm{min}$. Temperature: $24.5^{\circ} \mathrm{C}$. Sample length: $10 \mathrm{~cm}$. Sample width: $3 \mathrm{~cm}$. a) Freezing-defrosting cycles of gelation.
く, ほぼ一定の值を示している.タックの比較的良 好な検体は $c a .10^{4} \mathrm{dyne} / \mathrm{cm}^{2}$ の弾性率を示し, ダー ルキスト ${ }^{9)}$ が報告したゴム系の粘着剤の弾性率より 低いことが分かった。 また粘性項である損失 $\tan \delta$ は粘着性の良好な PVA 水溶液ゲルは粘着性の低い

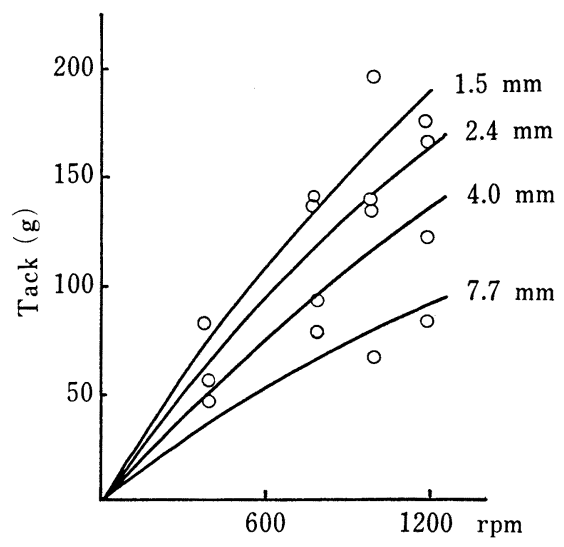

Fig. 7. Plot of Rolling Cylinder Tack as a Function of Velocity for PVA Hydrogels with Different Thickness

Sample: $15 \%$ aqueous solution of Poval K-20; freezing: $-5^{\circ} \mathrm{C}, 20 \mathrm{~h}$; defrosting: $20^{\circ} \mathrm{C}, 4 \mathrm{~h}$. Temperature: $20^{\circ} \mathrm{C}$. Radius of a cylinder: $1 \mathrm{~cm}$. 
TABle II. Conditions of Preparation, Tack and Viscoelasticities of PVA Hydrogels

\begin{tabular}{|c|c|c|c|c|c|c|c|}
\hline Sample $^{a)}$ & $\begin{array}{l}\text { Defrost. } \\
\text { temp. }\left({ }^{\circ} \mathrm{C}\right)\end{array}$ & $\begin{array}{c}\mathbf{F} / \mathbf{D} \\
\text { cycles }^{b)}\end{array}$ & $\underset{\left(\log S^{c)}\right)}{\operatorname{Rollinng}} \mathrm{S}$. & $\begin{array}{c}\text { Static } \\
\text { modulus } \\
\left(\mathrm{g} / \mathrm{cm}^{2}\right)\end{array}$ & $\begin{array}{c}\text { Storage } \\
\text { modulus } \\
\left(\text { dyne } / \mathrm{cm}^{2}\right)\end{array}$ & $\begin{array}{c}\text { Loss } \\
\text { modulus } \\
\left(\mathrm{dyne} / \mathrm{cm}^{2}\right)\end{array}$ & $\tan \delta^{e)}$ \\
\hline K-20 & 25 & 4 & 0.76 & 73.3 & $2.9 \times 10^{5}$ & $1.2 \times 10^{4}$ & 0.041 \\
\hline $\mathrm{K}-20$ & 25 & 3 & 1.11 & 77.6 & $2.0 \times 10^{5}$ & $0.9 \times 10^{4}$ & 0.045 \\
\hline$K-20$ & 25 & 2 & 1.31 & 41.5 & $1.5 \times 10^{5}$ & $0.8 \times 10^{4}$ & 0.053 \\
\hline K-20 & 25 & 1 & 2.08 & 21.6 & $8.2 \times 10^{4}$ & $1.1 \times 10^{4}$ & 0.134 \\
\hline K-17E & 25 & 1 & 2.25 & 13.4 & $5.9 \times 10^{4}$ & $0.9 \times 10^{4}$ & 0.152 \\
\hline K-24E & 25 & 1 & 1.08 & 46.1 & $1.9 \times 10^{5}$ & $1.2 \times 10^{4}$ & 0.063 \\
\hline K-20 & 5 & 1 & 2.23 & 30.6 & $1.7 \times 10^{5}$ & 1. $3 \times 10^{4}$ & 0.076 \\
\hline K-20 & 40 & 1 & 2.31 & 16.4 & $7.7 \times 10^{4}$ & $1.1 \times 10^{4}$ & 0.142 \\
\hline
\end{tabular}

a) PVA concentration in hydrogel: $15 \%$, freezing $-5^{\circ}, 20 \mathrm{~h}$.

b) F/D cycle: Times of freezing-defrosting cycle.

c) Logarithmic rolling stress.

d) Instantaneous rising gradient of tensile strength curve.

e) Apparatus: Rheolograph gel (Toyo Seiki); temp. $23^{\circ} \mathrm{C}$; weight: $10 \mathrm{~g}$; amplitude: $100 \mu$ m; period of vibration: $2 \mathrm{~Hz}$.

TABLE III. Correlation Matrix of Tack and Viscoelasticities of PVA Hydrogels

\begin{tabular}{|c|c|c|c|c|c|}
\hline & Tack & $\begin{array}{c}\text { Static } \\
\text { modulus }\end{array}$ & $\begin{array}{c}\text { Storage } \\
\text { modulus }\end{array}$ & $\begin{array}{c}\text { Loss } \\
\text { modulus }\end{array}$ & $\tan \delta$ \\
\hline Tack & 1.000 & & & & \\
\hline Static modulus & -0.897 & 1.000 & & & \\
\hline Storage modulus & -0.835 & 0.898 & 1.000 & & \\
\hline Loss modulus & 0.083 & -0.037 & 0.281 & 1.000 & \\
\hline $\tan \delta$ & 0.839 & -0.887 & -0.912 & -0.028 & 1.000 \\
\hline
\end{tabular}

Multiple correlation $R=0.9105$; contribution $R=82.901$; adjusted contribution $R=65.801$.

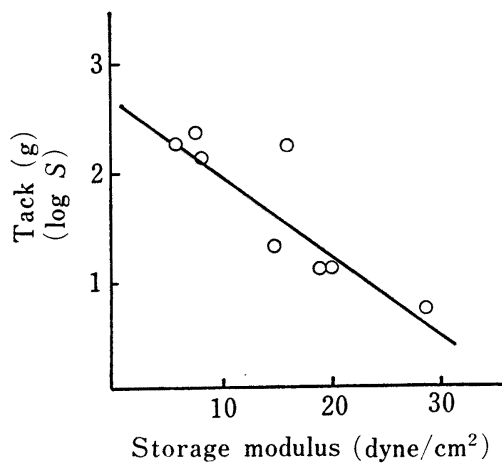

Fig. 9. Relation between Rolling Cylinder Tack and Storage Modulus of PVA Hydrogels

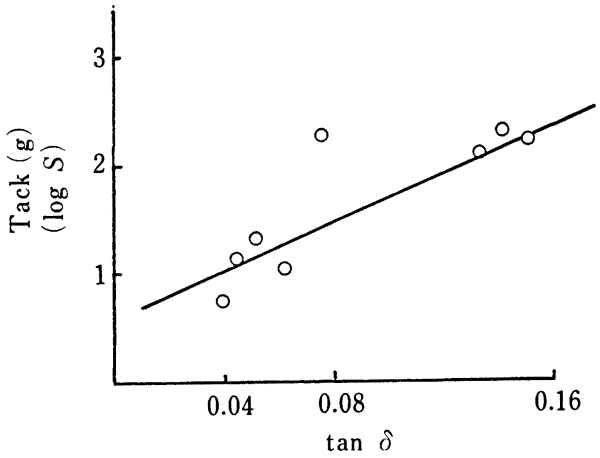

Fig. 10. Relation between Rolling Cylinder Tack and Loss Tangent of PVA Hydrogels

ものに比べ, 約 3 倍程度高いことが分かる.

Table II に示したように PVA の種類, 製造法によりタック及び粘弾性が変化することから統計処理を行い相 関マトリックスを作成し Table III に示した.

タックに対し静的弾性パラメーター, 貯蔵弾性率及び損失 $\tan \delta$ は高い相関性を示し, 粘着剂のタックあるい は粘着性などの粘着特性は，その粘弾性を測定すれば推定できることが分かる(寄与率 $82.9 \%$ ).

また静的弾性パラメーターは貯蔵弾性及び損失 $\tan \delta$ とも高い相関性を有することが分かる. 
静的弾性パラメーターは便宜的な数值なので, PVA の種類及び製造条件が同一であり, 統計的に比較的相関 性の高いPVA 水溶液ゲルの貯蔵弾性率及び損失 $\tan \delta$ とタックの関係を示したものが Fig. 9, 及び Fig. 10 で ある.いずれも高い相関性が得られる。

\section{結 語}

1. 完全ケン化型 PVA 水溶液は凍結解凍を繰り返す事により, 高含水で高弾性の含水ゲルを作製することが でき, 成形湿布剂の基剤などの応用が可能である.

2. PVA 水溶液ゲルの粘着性と粘弾性は統計処理により相関マトリックスを作成し比較した結果, 貯蔵弾性 率及び損失 $\tan \delta$ に高い相関性を示す. また便宜的な数值であるが静的弾性パラメーターとも高い相関性を示す. すなわち PVA 水溶液ゲルは，その粘弾性的性質を測定することにより，粘着性を推定することが可能である.

\section{引用文献及び注}

1) 渡瀬峰男, 日化誌, 1983, 973.

2) N. Peppas, E. W. Merrill, J. Appl. Polymer Sci., 20, 1457 (1976).

3）竹内寿一郎, 柿沼 薫, “統計解析プログラム集,” 工学図書株式会社, 1984, pp. 125-140.

4) JIS Z-0237 Tack Testing Device.

5）医薬品製造指針, 日本公定書協会, 1984, p. 51.

6) 水町 浩, 日本接着協会誌, 20, 522 (1984).

7) 玄 丞焦, 筏 義人, 第 33 回高分子学会年次大会予稿集, 名古屋, 5 月, 1984, p. 862 .

8) 水町 浩, 山口 洋, 漆崎文男, 日本接着学会誌, 未発表データ.

9) Dahlquist, “Adhesion Fundamental and Practice," C.A., 1966, p. 143. 